\title{
Erratum to: The impact of postpartum cervical tear on the occurrence of preterm birth in subsequent pregnancy
}

\author{
Noah Zafran ${ }^{1,2} \cdot$ Eden Gerszman $^{2} \cdot$ Gali Garmi $^{1,2} \cdot$ Sivan Zuarez-Easton ${ }^{1}$. \\ Raed Salim ${ }^{1,2}$ (])
}

Published online: 30 August 2017

(C) Springer-Verlag GmbH Germany 2017

\section{Erratum to: Arch Gynecol Obstet}

(2017) 296:199-204

DOI 10.1007/s00404-017-4410-0

In original publication, the family name of one of the coauthor (Zuaretz-Easton S) was incorrect. The correct family name has been given below:

The correct family name is Zuarez-Easton $\mathrm{S}$.

The online version of the original article can be found under doi:10.1007/s00404-017-4410-0.

Raed Salim

salim_ra@clalit.org.il

1 Department of Obstetrics and Gynecology, Emek Medical Center, 18101 Afula, Israel

2 The Ruth and Bruce Rappaport Faculty of Medicine, Technion, Haifa, Israel 